Article

\title{
Kinetic Study of the Pyrolysis of Waste Printed Circuit Boards Subject to Conventional and Microwave Heating
}

\author{
Jing Sun, Wenlong Wang, Zhen Liu, Qingluan Ma, Chao Zhao and Chunyuan Ma *
}

National Engineering Laboratory for Coal-fired Pollutants Emission Reduction, Energy and Power Engineering School, Shandong University, 17923 Jingshi Road, Jinan, Shandong 250061, China; E-Mails: sunjing0108@163.com (J.S.); wwenlong@sdu.edu.cn (W.W.); lzadu@163.com (Z.L.); mqlsdu@163.com (Q.M.); langyue0507@126.com (C.Z.)

* Author to whom correspondence should be addressed; E-Mail: sdetechym@163.com;

Tel.: +86-531-88399369; Fax: +86-531-88395877.

Received: 2 July 2012; in revised form: 8 August 2012 / Accepted: 24 August 2012 /

Published: 31 August 2012

\begin{abstract}
This paper describes a kinetic study of the decomposition of waste printed circuit boards (WPCB) under conventional and microwave-induced pyrolysis conditions. We discuss the heating rates and the influence of the pyrolysis on the thermal decomposition kinetics of WPCB. We find that the thermal degradation of WPCB in a controlled conventional thermogravimetric analyzer (TGA) occurred in the temperature range of $300{ }^{\circ} \mathrm{C}-600{ }^{\circ} \mathrm{C}$, where the main pyrolysis of organic matter takes place along with an expulsion of volumetric volatiles. The corresponding activation energy is decreased from $267 \mathrm{~kJ} / \mathrm{mol}$ to $168 \mathrm{~kJ} / \mathrm{mol}$ with increased heating rates from $20^{\circ} \mathrm{C} / \mathrm{min}$ to $50{ }^{\circ} \mathrm{C} / \mathrm{min}$. Similarly, the process of microwave-induced pyrolysis of WPCB material manifests in only one stage, judging by experiments with a microwave power of $700 \mathrm{~W}$. Here, the activation energy is determined to be only $49 \mathrm{~kJ} / \mathrm{mol}$, much lower than that found in a conventional TGA subject to a similar heating rate. The low activation energy found in microwave-induced pyrolysis suggests that the adoption of microwave technology for the disposal of WPCB material and even for waste electronic and electrical equipment (WEEE) could be an attractive option.
\end{abstract}

Keywords: kinetic study; microwave-induced pyrolysis; waste printed circuit boards (WPCB); activation energy 


\section{Nomenclature:}

\begin{tabular}{|c|c|}
\hline A & Pre-exponential factor, $\mathrm{s}^{-1}$ \\
\hline $\mathrm{E}$ & Activation energy, $\mathrm{kJ} / \mathrm{mol}$ \\
\hline $\mathrm{f}$ & Function of conversion \\
\hline $\mathrm{k}$ & Thermal decomposition rate constant, $\mathrm{s}^{-1}$ \\
\hline $\mathrm{n}$ & Reaction order \\
\hline $\mathrm{R}$ & Gas constant $=8.314 \mathrm{~kJ} /(\mathrm{kmol} \mathrm{K})$ \\
\hline $\mathrm{t}$ & Pyrolysis time, $\mathrm{s}$ \\
\hline $\mathrm{T}$ & Absolute temperature, $\mathrm{K}$ \\
\hline $\mathrm{T}_{0}$ & The temperature at which the pyrolysis of WPCB begin, ${ }^{\circ} \mathrm{C}$ \\
\hline $\mathrm{T}_{1 \mathrm{~m}}$ & The temperature at which the DTG curve of WPCB reaches the first peak, ${ }^{\circ} \mathrm{C}$ \\
\hline $\mathrm{T}_{2 \mathrm{~m}}$ & The temperature at which the DTG curve of WPCB reaches the second peak, ${ }^{\circ} \mathrm{C}$ \\
\hline W & Weight of sample at time $\mathrm{t}, \mathrm{mg}$ and/or $\mathrm{g}$ \\
\hline $\mathrm{W}_{0}$ & Initial weight of sample, $\mathrm{mg}$ and/or $\mathrm{g}$ \\
\hline $\mathrm{W}_{\infty}$ & Final weight of sample, mg and/or $\mathrm{g}$ \\
\hline $\mathrm{x}$ & Conversion of WPCB, defined as: $\mathrm{x}=\mathrm{w}_{0}-\mathrm{w} /\left(\mathrm{w}_{0}-\mathrm{w}_{\infty}\right)$ \\
\hline Greek letters & Descriptions \\
\hline$\beta$ & Heating rate, ${ }^{\circ} \mathrm{C} \min ^{-1}$ \\
\hline
\end{tabular}

\section{Introduction}

Due to the rapid development of technology, the lifespan of electrical and electronic equipment (EEE) is very short, resulting in increasing quantities of waste electronic and electrical equipment (WEEE). It is estimated that some 40-60 million tons of WEEE are generated worldwide every year, which poses grave risks to human health and the environment [1,2]. However, in spite of its hazardous properties, WEEE is also considered a precious resource, so the development of effective WEEE recycling techniques is of increasing interest. As one of the most important branches of the WEEE stream, waste printed circuit boards (WPCB) are generally considered to be representative of WEEE, and have received increasing attention from the public and researchers because they contain a wealth of nonferrous metals in addition to a variety of toxic materials [3,4]. Thus, the recycling of WPCB is important not only as regards environmental protection and the recovery of valuable materials, but also for providing guidance to WEEE recycling.

Pyrolysis can be described as the thermal decomposition of organic components in an oxygen-free atmosphere to yield char, oil, and gas, and it holds promise as an approach to optimal waste upgrading, especially for organic polymers. Moreover, operational conditions in pyrolytic processes can be optimized to improve the yield or the quality of desirable products by means of innovative heating methods or catalysts. Microwave pyrolysis (MWP) is one focus of current research and has drawn the widespread interest of foreign and domestic researchers [5-8]. The applications of MWP include the pyrolysis of plastic waste [5,6], the pyrolysis of biomass waste [7-13], sewage sludge [14,15], and waste automotive engine oil [16-18], among others. 
Although several groups have studied the pyrolysis of WPCB, their focus has mainly been on the pyrolytic kinetics [19-22] and the formation and fate of brominated compound [22-24] in conventional heating schemes (such as electric heating), also known as conventional pyrolysis. Due to the presence of metals, which are considered incompatible with microwave heating, the microwave-induced pyrolysis of WPCB has barely been studied. Under microwave irradiation, a discharge will be triggered when there are metal tips or sharp corners in the material being treated. This is a result of field enhancement and field emission of electrons when the induced electric potential exceeds the coulomb potential. As a result of these discharges, metal tips can be melted, implying that a discharge can produce local temperatures of $1000{ }^{\circ} \mathrm{C}-2000{ }^{\circ} \mathrm{C}$ [25-27]. Our research group has studied the heating effects associated with microwave-metal discharges and found that the energy conversion ratio from electrical energy to heat can reach as high as $30 \%$ [28]. Based on the unique material characteristics of WPCBs and the discharge properties of metals, we have previously established that microwave-induced pyrolysis holds promise as a way to process WPCBs [26-30].

Kinetics studies of microwave-induced pyrolysis of WPCBs have rarely been performed. However, an understanding of the pyrolytic kinetics is important for reactor design, process optimization, and the general improvement of microwave heating applications. This calls for the development of thermal decomposition kinetic models that can accurately predict the pyrolysis processes that occur in WPCBs under microwave irradiation. The prevailing thermal gravimetric analysis (TGA) technique is able to predict such thermal decomposition processes quite accurately, and is considered to be representative of conventional pyrolysis modeling. In this work, the pyrolytic kinetics of WPCBs subject to both conventional heating and microwave heating are studied. We present and compare kinetic parameters of interest that include the activation energy, a pre-exponential factor, and the reaction order in the chemical reaction-controlled region. These data may be of use in recycling process design and in energy recovery schemes for WPCB reuse in pyrolytic processes.

\section{Materials and Methods}

\subsection{Materials and Sample Preparation}

Waste samples of printed circuit boards, obtained from a recycling plant in Jinan, China, served as the raw material for our studies. The WPCBs were first shredded into fragments of about $1 \mathrm{~cm} \times 1 \mathrm{~cm}$ (referred to as "big particles"), and then a representative fragment was sampled and crushed into a fine particle state (approximately 40-60 mesh) in the laboratory. The proximate analysis of WPCBs was carried out by referring to the coal proximate analysis method. The weight percentages of moisture, ash, volatiles and fixed carbon were $0.48 \%, 73.62 \%, 25.12 \%$ and $0.78 \%$, respectively.

\subsection{Apparatus and Procedures}

The pyrolysis experiments were carried out in a thermogravimetric analyzer (Mettler-Toledo, TGA/DSC/1600HT) for the conventional heating data, and in a modified household microwave oven (Galanz P7021TP-6) for the microwave-induced pyrolysis experiments. For the conventional TGA of WPCB, about $15.0 \mathrm{mg}$ of fine particle material was placed in a crucible pan and heated in an inert atmosphere of nitrogen $\left(\mathrm{N}_{2}\right.$ flow rate of $\left.20 \mathrm{~mL} / \mathrm{min}\right)$ over a temperature range of $50-900{ }^{\circ} \mathrm{C}$ at heating 
rates of $10,20,30$ and $50{ }^{\circ} \mathrm{C} / \mathrm{min}$. The temperature and weight of the material was monitored with a computer. For the microwave-induced pyrolysis of WPCB, $40 \mathrm{~g}$ of "big particle" material was placed in a quartz tube (60 mm length, $55 \mathrm{~mm}$ i.d.) which was itself surrounded by a quartz container and purged with nitrogen ( $99.999 \%$ pure) at a flow rate of $100 \mathrm{~mL} / \mathrm{min}$. During microwave irradiation, the temperature was measured by two ways: one is an online measurement by placing the thermocouple $5 \mathrm{~mm}$ directly above the sample to monitoring the temperature of volatility; the other is an offline measurement by setting different irradiation time (e.g., $40 \mathrm{~s}, 60 \mathrm{~s}, 90 \mathrm{~s}, 120 \mathrm{~s}, 150 \mathrm{~s}, 3 \mathrm{~min}$, $5 \mathrm{~min}, . .$.$) and inserting the thermocouple into the center of the sample immediately after turning off$ microwaves. The thermocouple we used was connected with a filter capacity to reduce the disturbance from microwaves and improve the reliability of the temperature measurement. The offline temperature measurement was used to correct the online measurement results by averaging at certain time points. Concurrently, the sample mass when the thermocouple centered $5 \mathrm{~mm}$ directly above was recorded via an electronic balance system underneath. Figure 1 shows a diagram of the experimental setup.

Figure 1. Experimental set-up for microwave pyrolysis of WPCB: (1) microwave generation system; (2) microwave control system; (3) thermocouple; (4) temperature monitoring system; (5) PTFE tray system; (6) quartz container; (7) weighing system; (8) signal acquisition and processing system; (9) nitrogen and (10) microwave oven.

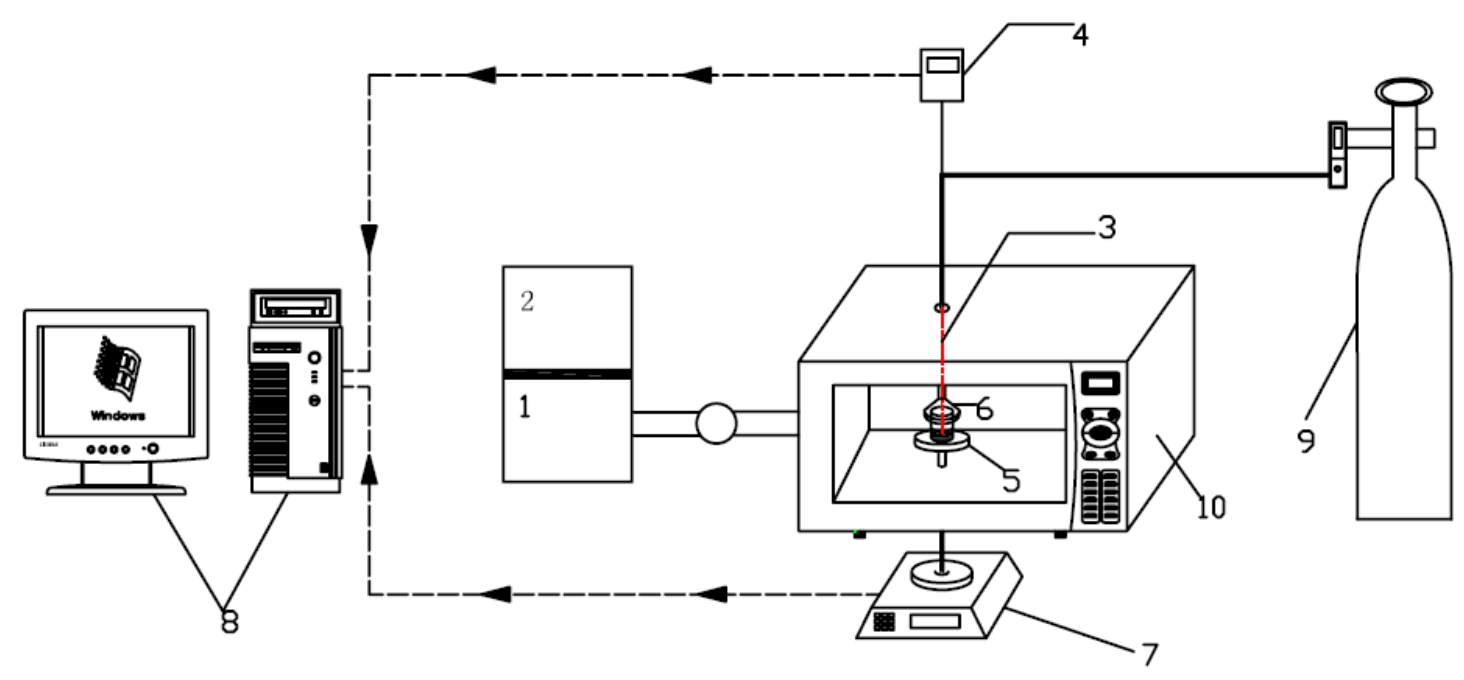

\subsection{Pyrolysis Kinetics}

Pyrolysis of WPCB is generally a complex process. It is difficult to discover a full kinetic analysis of complex systems, but some kind of "effective" or "average" kinetic description is still needed. In this work, the overall rate of the pyrolytic reactions of WPCB is described by the following equation:

$$
\frac{\mathrm{dx}}{\mathrm{dt}}=\mathrm{kf}(\mathrm{x})
$$

where $f(x)$ is a function depending on the decomposition mechanism, which can be in the form of an nth order of reaction: $f(x)=(1-x)^{n}$.

Constant k obeys the Arrhenius correlation: 


$$
\mathrm{k}=\mathrm{A} \exp \left(-\frac{\mathrm{E}}{\mathrm{RT}}\right)
$$

Rearranging and integrating, we have:

$$
\int_{0}^{\mathrm{x}} \frac{\mathrm{dx}}{(1-\mathrm{x})^{\mathrm{n}}}=\frac{\mathrm{A}}{\beta} \int_{\mathrm{T}_{0}}^{\mathrm{T}} \exp (-\mathrm{E} / \mathrm{RT}) \mathrm{dT}
$$

Based on Equation (3), Coats-Redfern's method was derived for numerical determination of the kinetic parameters, as Equations (4) and (5):

when $\mathrm{n} \neq 1$ :

$$
\ln \left\{\frac{1-(1-x)^{1-n}}{T^{2}(1-n)}\right\}=\ln \left[\frac{A R}{\beta E}\left(1-\frac{2 R T}{E}\right)\right]-\frac{E}{R T}
$$

when $\mathrm{n}=1$ :

$$
\ln \left\{\frac{-\ln (1-x)}{T^{2}}\right\}=\ln \left[\frac{A R}{\beta E}\left(1-\frac{2 R T}{E}\right)\right]-\frac{E}{R T}
$$

When 2RT/E is small enough to be ignored, Equations (4) and (5) can be simplified as Equations (6) and (7):

when $\mathrm{n} \neq 1$ :

$$
\ln \left\{\frac{1-(1-x)^{1-n}}{T^{2}(1-n)}\right\}=\ln \left(\frac{A R}{\beta E}\right)-\frac{E}{R T}
$$

when $\mathrm{n}=1$ :

$$
\ln \left\{\frac{-\ln (1-\mathrm{x})}{\mathrm{T}^{2}}\right\}=\ln \left(\frac{\mathrm{AR}}{\beta \mathrm{E}}\right)-\frac{\mathrm{E}}{\mathrm{RT}}
$$

With regards the scenario that RT/E is not negligible, the Equations (4) and (5) can be transformed into Equations (8) and (9):

when $\mathrm{n} \neq 1$ :

$$
\ln \left\{\frac{1-(1-\mathrm{x})^{1-n}}{\mathrm{~T}^{2}(1-\mathrm{n})\left(1-\frac{2 \mathrm{RT}}{\mathrm{E}}\right)}\right\}=\ln \frac{\mathrm{AR}}{\beta \mathrm{E}}-\frac{\mathrm{E}}{\mathrm{RT}}
$$

when $\mathrm{n}=1$ :

$$
\ln \left\{\frac{-\ln (1-x)}{T^{2}\left(1-\frac{2 R T}{E}\right)}\right\}=\ln \frac{A R}{\beta E}-\frac{E}{R T}
$$

Iterative method and the least squares method should be combined to determine the value of $n, A$ and $E$. 


\section{Results and Discussion}

\subsection{Conventional Pyrolysis of WPCBs Using TGA}

The TG and DTG curves from the conventional heating experiments are shown in Figure 2. As evidenced by the DTG curve, there may be two overlapped degradation stages due to the presence of a turning point around $430{ }^{\circ} \mathrm{C}$. However, there were no obvious divide between these two stages, thus it can be considered that one degradation stage was found during the pyrolysis process, characterized by an obvious weight loss peak. The main decomposition occurred at $300{ }^{\circ} \mathrm{C}-600{ }^{\circ} \mathrm{C}$ with an accompanying conversion of about $90 \%$. The main thermal degradation temperature in this paper were a little high when compared to the work of Chen et al. [19] and Chiang et al. [31] which could be caused by high heating rates and different compositions. Thus, the general weight loss in the WPCBs can be characterized by the following stages: the weight of the sample barely changed when its temperature remained below $300{ }^{\circ} \mathrm{C}$; thereafter the sample underwent a rapid weight loss in the temperature range of $300{ }^{\circ} \mathrm{C}-600{ }^{\circ} \mathrm{C}$. This weight loss process comprised the pyrolysis phase, where about $25 \%$ of the original weight was lost. Subsequently, the weight of the sample was largely maintained with a very slow weight loss process.

Figure 2. Thermogravimetry curves (a) and derivative thermogravimetry curves (b) at different heating rates.

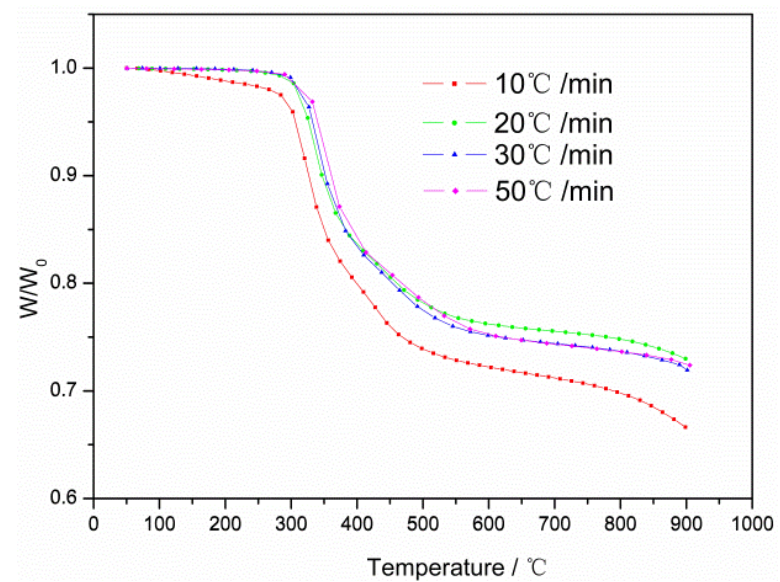

(a)

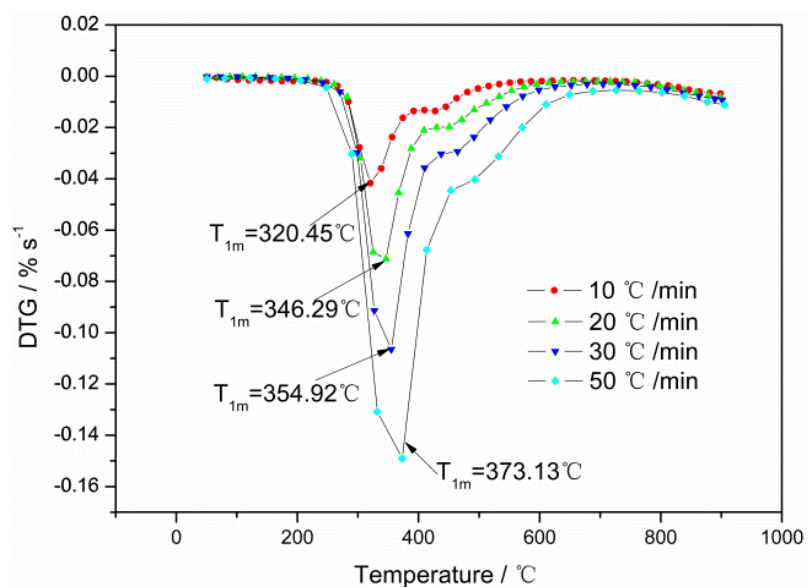

(b)

With increased heating rates, the characteristic temperatures of $T_{0}, T_{1 m}, T_{2 m}$ (description in nomenclature, $\mathrm{T}_{2 \mathrm{~m}}$ was not marked in Figure 2 due to the vague division between the second peak and the first one) were increased, the DTG curve was shifted towards higher temperature regions, and the value of $\mathrm{dx} / \mathrm{dt}$ and the maximum decomposition rates were also improved. We can conclude that the pyrolysis reaction was postponed to higher temperature range with increasing heating rates, because the time interval in which the sample is exposed to a given temperature decreases as the heating rate increases. This result is in accordance with the work of other researchers. The final residual weight rate was strongly influenced by variations in the heating rate. The residual weight rate decreased as a result of mass-loss during thermal decomposition, indicating volatile matter was ejected. With low heating rates, the time interval in which the sample is exposed to a given temperature is long, so that the 
sample has ample time to decompose, improving the reaction depth. As many metal components including the metals with low melting or boiling points, such as $\mathrm{Hg}, \mathrm{Sn}, \mathrm{Pb}, \mathrm{Zn}$, etc., were contained in WPCBs, long residence time may intensified the volatility or emission of heavy metal components. Moreover, compared to the proximate analysis results of WPCBs, WPCBs can obtain a complete pyrolysis with the heating rates from $20^{\circ} \mathrm{C} / \mathrm{min}$ to $50{ }^{\circ} \mathrm{C} / \mathrm{min}$. Thus, the following kinetic study of the pyrolysis process is based mainly on the heating rates of 20,30 and $50{ }^{\circ} \mathrm{C} / \mathrm{min}$.

As most materials decompose (about 90\% conversion occurred) in the temperature range of $300{ }^{\circ} \mathrm{C}-600{ }^{\circ} \mathrm{C}$, which comprises the main reaction region, the kinetic study of the thermal decomposition in this temperature range is the main focus of our work. The Coats-Redfern method was used to determine the kinetic parameters for heating rates of 20,30 , and $50{ }^{\circ} \mathrm{C} / \mathrm{min}$ and their values are shown in Table 1.

Table 1. Kinetic parameters for conventional pyrolysis of WPCB at three heating rates.

\begin{tabular}{ccccc}
\hline $\boldsymbol{\beta}\left({ }^{\circ} \mathbf{C} / \mathbf{m i n}\right)$ & $\mathbf{n}$ & $\mathbf{E}$ & $\ln \mathbf{A}$ & $\mathbf{R}^{\mathbf{2}}$ \\
\hline 20 & 8.97 & 266.52 & 53.51 & 0.996 \\
30 & 7.36 & 219.62 & 43.69 & 0.997 \\
50 & 5.46 & 168.78 & 33.22 & 0.997 \\
\hline
\end{tabular}

The activation energy was found to be $168-267 \mathrm{~kJ} / \mathrm{mol}$, decreasing with an increase in heating rate. Our results indicate a significant difference in activation energy for different heating rates. The variation of the activation energy with heating rate gives rise to a variation in the pre-exponential factor. This can be explained with a kinetic compensation effect that can be expressed as a linear relationship between the logarithm of the pre-exponential factor and the activation energy $(\ln (A)=k E+b)$. This effect is mainly due to mathematical, physio-chemical, and experimental causes, which is widely researched [32,33]. Although this coupling of the kinetic parameters can result in similar values of the kinetic constant, the lower activation energy indicates the energy required to activate molecules to start the chemical reaction is lower because chemical reaction occurs on the condition that the molecular energy is equal to or higher than the activation energy. And more molecules will be activated at a given temperature, if the activation energy is lower. Although it is hard to observe the differences of the start of decomposition at different heating rates in Figure 2, which are mainly due to reaction shifts to a high temperature range with the increased heating rate, the reaction rate at a given temperature was obviously improved with the increase in heating rate, as illustrated in Figure 2b. The accelerated reaction rate can be attributable to the strengthened activation of molecules due to lower activation energy. The reaction order was also decreased with an increase in heating rate which demonstrated the thermal decomposition process was very complex when the heating rate was low. And a high heating is beneficial to eliminate unnecessary reactions to make the decomposition process simple.

\subsection{Microwave-induced Pyrolysis of WPCB}

The heating rate of WPCB material subject to microwave irradiation is determined by many factors, such as the sample's wave-absorption capacity and the heating effect from microwave-metal discharges. Thus, in contrast to the heating rates in conventional heating schemes, it is much easier to control the microwave power in experiments involving microwave-induced pyrolysis of WPCBs. 
Figure 3 presents the temperature, residual weight rate and DTG of WPCBs as a function of time when exposed to an incident microwave power of $700 \mathrm{~W}$ at $2.45 \mathrm{GHz}$. The temperature of the sample clearly skyrockets at the beginning of these experiments, and then is followed by an approximately linear increase with a measured heating rate of about $140{ }^{\circ} \mathrm{C} / \mathrm{min}$ in the range of $250{ }^{\circ} \mathrm{C}-500{ }^{\circ} \mathrm{C}$, followed by an increase in temperature to above $600{ }^{\circ} \mathrm{C}$ at a lower rate of about $60{ }^{\circ} \mathrm{C} / \mathrm{min}$, and finally it stabilizes at a temperature of about $650{ }^{\circ} \mathrm{C}$. Correspondingly, the decomposition of WPCBs can be divided into two stages: the sample was rapidly pyrolyzed with a rapid rate of weight loss at temperatures below $500{ }^{\circ} \mathrm{C}$, after which the samples experienced a slow weight loss process.

Figure 3. T-t, TG-t, and DTG-t curves of WPCBs in the microwave pyrolysis process.

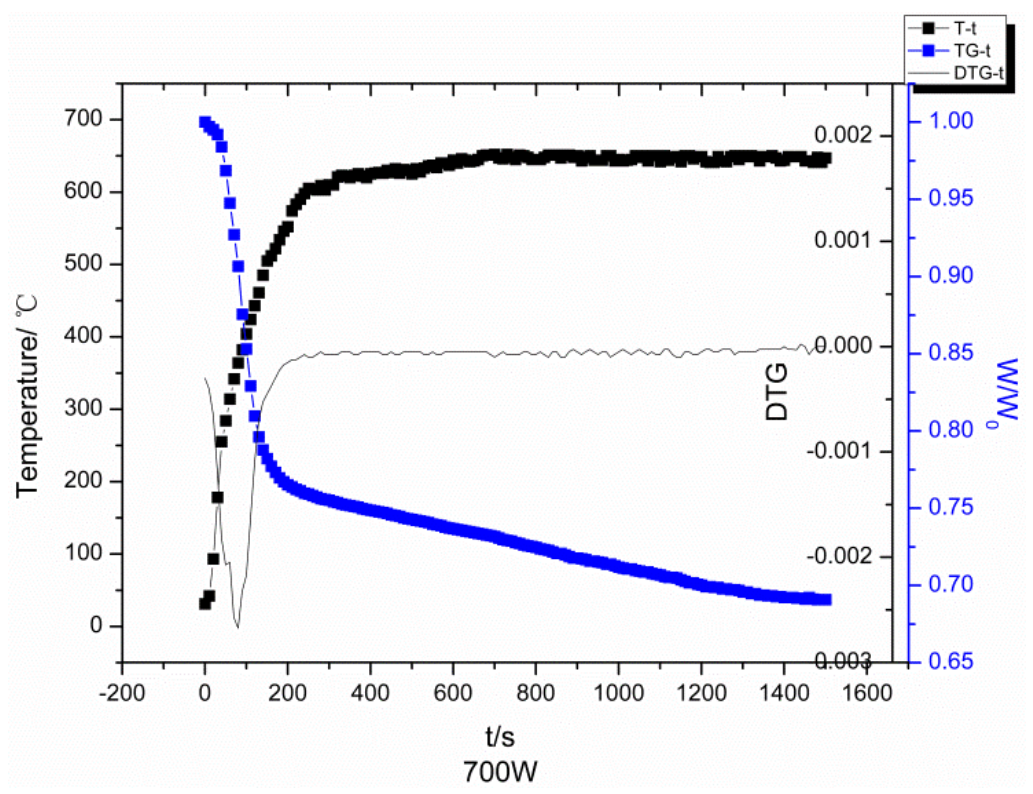

For a better comparison, a simulation of microwave-induced pyrolysis of WPCB material was carried out by modeling a conventional TGA with a heating rate of $140{ }^{\circ} \mathrm{C} / \mathrm{min}$ from $50{ }^{\circ} \mathrm{C}$ to $900{ }^{\circ} \mathrm{C}$, and subsequent temperature maintenance at $900{ }^{\circ} \mathrm{C}$ for $20 \mathrm{~min}$. In fact, it is hard to simulate the heating process of WPCB under microwave irradiation completely. Thus, a simulation of the main pyrolysis phase was simulated. Figure 4 presents the temperature, residual weight rate and DTG of WPCB as a function of time.

Compared with Figure 3, which shows real data from microwave experiments, the overall profiles are similar, except for the lack of an induction phase in the microwave-induced pyrolysis data, since metal-microwave sparks occurred immediately at the onset of microwave irradiation, leading to high local temperatures and a partial decomposition of WPCBs which results in significant weight loss, even though the average overall temperature may be low. As there is only one obvious peak in the data for the pyrolysis stage where the main reaction happened in both pyrolysis processes, our thermal kinetic study will be focused on this range.

It should be noted that the value of the pre-exponential factor $\mathrm{A}$ and the activation energy $\mathrm{E}$ is a number that is conditioned upon a constant heating rate during the entire pyrolysis process. For the microwave-induced pyrolysis experiments, the temperature curves have an approximately linear phase in the temperature range of $250^{\circ} \mathrm{C}-500{ }^{\circ} \mathrm{C}$. 
Figure 4. T-t, TG-t, and DTG- $t$ curves of WPCBs in simulation of the conventional heating process with a heating rate of $140{ }^{\circ} \mathrm{C} / \mathrm{min}$.

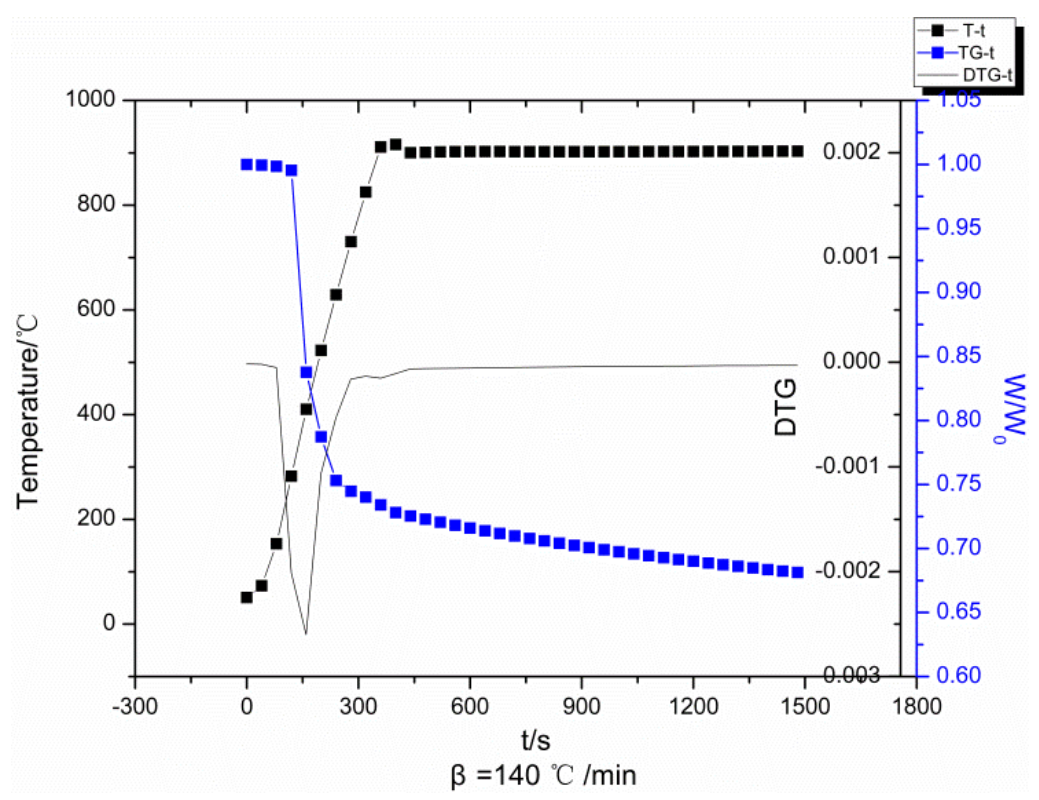

Thus, the heating rate during this phase can be considered constant. The following kinetic parameters were calculated based on the data related to this phase. For the simulated TGA, the main pyrolysis phase starts at $280{ }^{\circ} \mathrm{C}$, and this linear phase lies in the temperature range of $280{ }^{\circ} \mathrm{C}-530{ }^{\circ} \mathrm{C}$. The values of the calculated kinetics parameters are shown in Table 2.

Table 2. Kinetic parameters for pyrolysis of WPCB under both conventional TGA and microwave heating scheme.

\begin{tabular}{lcccc}
\hline Pyrolysis method & $\mathbf{n}$ & $\mathbf{E}$ & $\ln \mathbf{A}$ & $\mathbf{R}^{\mathbf{2}}$ \\
\hline Microwave power & 2.41 & 48.68 & 9.50 & 0.992 \\
Simulated TGA & 6.90 & 106.20 & 22.10 & 0.990 \\
\hline
\end{tabular}

Two main differences can be easily observed between the microwave pyrolysis process and the conventional process: one is the sequence of events at the beginning of the pyrolysis reaction; the other one is the activation energy of the main pyrolysis phase. As to the differences in the pyrolysis start, WPCB was pyrolyzed with weight loss at the onset of microwave irradiation, compared with an induction phase of about $100 \mathrm{~s}$ in the simulated pyrolysis process. The promotion effect on reaction start caused by microwave irradiation is mainly due to metal-microwave discharge as mentioned above. With regard to the activation energy, it should be same under the same heating rates if the kinetic processes in both cases are same. The fact that the activation energy in microwave heating is remarkably lower than that in conventional heating indicates that the kinetics in microwave heating is different from that in conventional heating schemes. With respect to the application of microwave heating to chemical reactions, both "thermal effect" and "non-thermal effect" are put forward and discussed. Here, the kinetics for microwave pyrolysis process can be attributable to the microwave internal heating style, wherein samples are heated uniformly, leading to reductions in temperature gradients in the sample and a reduced heat loss via conduction: more heat in the sample facilitates 
chemical reactions [33]. Moreover, the microwave-metal discharge plasma may be also beneficial in driving chemical reactions, as a result of "non-thermal" effects or a thermal catalyst-type effect. Due to the remarkably reduced activation energy caused by microwave heating style, certain special effects (i.e., non-thermal effects) can be concluded to contribute to the reaction kinetics.

In conclusion, the pyrolysis kinetics of WPCB subject to microwave heating are different from those in conventional heating, which makes the research on microwave-induced pyrolysis of waste very worthwhile. The results will help us further our research on microwave pyrolysis of electronic waste and other similar waste. And, more work is required to investigate the non-thermal effect of microwave heating on activation energy in the future.

\section{Conclusions}

This work describes a kinetic study of the thermal decomposition of WPCBs subject to both conventional TGA electric heating and a microwave thermogravimetric system, although the experimental conditions such as particle size, sample mass, flow rate of purge gas, etc., were different in the microwave pyrolysis $v s$. conventional TGA experiments. Our results indicate that the activation energy is decreased significantly with increasing heating rates for the thermal decomposition of WPCB material. The pre-exponential factor changed with activation energy mainly as a result of a kinetic compensation effect. When WPCB material was inundated with $2.45 \mathrm{GHz}$ microwaves, a rapid heating process took place, with a volumetric expulsion of volatile matter that occurs immediately after the sample exposure to microwaves. Compared with a simulated conventional TGA incorporating a similar heating rate, the activation energy in microwave-induced pyrolysis is much smaller. This can be attributed to the internal-type heating style and a catalyst effect caused by the presence of microwave heating or microwave-metal discharges. A high disposal efficiency and low activation energy indicated by the microwave-induced pyrolysis of WPCBs makes the adoption of microwave technology an attractive approach for the disposal of WPCBs and even WEEE materials.

\section{Acknowledgments}

The authors thank the support of Program for New Century Excellent Talents in University (NCET-10-0529).

\section{References}

1. Schwarzer, S; de Ono, A.; Peduzzi, P.; Giuliani, G.; Kluser, S. E-Waste, the Hidden Side of IT Equipment's Manufacturing and Use; Environment Alert Bulletin; United Nations Environment Programme: Geneva, Switzerland, 2005. Available online: http://www.grid.unep.ch/products/ 3_Reports/ew_ewaste.en.pdf (accessed on 5 May 2005).

2. Guo, J.; Guo, J.; Xu, Z. Recycling of non-metallic fractions from waste printed circuit boards: A review. J. Hazard. Mater. 2009, 168, 567-590.

3. Byers, T.J. Printed Circuit Board Design with Microcomputer; McGraw-Hill: New York, NY, USA, 1991. 
4. Das, A.; Vidyadhar, A.; Mehrotra S.P. A novel flowsheet for the recovery of metal values from waste printedcircuit boards. Resour. Conserv. Recycl. 2009, 53, 464-469.

5. Hussain, Z.; Khan, K.M.; Hussain, K. Microwave-metal interaction pyrolysis of polystyrene. J. Anal. Appl. Pyrolysis 2010, 89, 39-43.

6. Ludlow-Palafox, C.; Chase, H.A. Microwave-induced pyrolysis of plastic wastes. Ind. Eng. Chem. Res. 2001, 40, 4749-4756.

7. Miura, M.; Kaga, H.; Sakurai, A.; Kakuchi, T.; Takahashi, K. Rapid pyrolysis of wood block by microwave heating. J. Anal. Appl. Pyrolysis 2004, 71, 187-199.

8. Huang, Y.F.; Kuan, W.H.; Lo, S.L.; Lin, C.F. Hydrogen-rich fuel gas from rice straw via microwave-induced pyrolysis. Bioresour. Technol. 2010, 101, 1968-1973.

9. Du, Z.; Li, Y.; Wang, X.; Wan, Y.; Chen, Q.; Wang, C.; Lin, X.; Chen, P.; Ruan, R. Microwave-assisted pyrolysis of microalgae for biofuel production. Bioresour. Technol. 2011, 102, 4890-4896.

10. Zhao, X.Q.; Song, Z.L.; Liu, H.Z.; Li, Z.Q.; Li, L.Z.; Ma, C.Y. Microwave pyrolysis of corn stalk bale: A promising method for direct utilization of large-sized biomass and syngas production. J. Anal. Appl. Pyrolysis 2010, 89, 87-94.

11. Zhao, X.Q.; Zhang, J.; Song, Z.L.; Liu, H.Z.; Li, L.Z.; Ma, C.Y. Microwave pyrolysis of straw bale and energy balance analysis. J. Anal. Appl. Pyrolysis 2011, 92, 43-49.

12. Domínguez, A.; Menéndez, J.A.; Fernández, Y.; Pis, J.J.; Valente, J.M.N.; Carrott, P.J.M.; Ribeiro Carrott, M.M.L. Conventional and microwave induced pyrolysis of coffee hulls for the production of a hydrogen rich fuel gas. J. Anal. Appl. Pyrolysis 2007, 79, 128-135.

13. Elharfia, K.; Mokhlisse, A.; Chanâa, M.B.; Outzourhit, A. Pyrolysis of the Moroccan (Tarfaya) oil shales under microwave irradiation. Fuel 2000, 79, 733-742.

14. Menéndez, J.A.; Domínguez, A.; Inguanzo, M.; Pis, J.J. Microwave-induced drying, pyrolysis and gasification (MWDPG) of sewage sludge: Vitrification of the solid residue. J. Anal. Appl. Pyrolysis 2005, 74, 406-412.

15. Menéndez, J.A.; Domínguez, A.; Inguanzo, M.; Pis, J.J. Microwave pyrolysis of sewage sludge: Analysis of the gas fraction. J. Anal. Appl. Pyrolysis 2004, 71, 657-667.

16. Lam, S.S.; Russell, A.D.; Lee, C.L.; Chase, H.A. Microwave-heated pyrolysis of waste automotive engine oil: Influence of operation parameters on the yield, composition, and fuel properties of pyrolysis oil. Fuel 2012, 92, 327-329.

17. Lam, S.S.; Russell, A.D.; Lee, C.L.; Lam, S.K.; Chase, H.A. Production of hydrogen and light hydrocarbons as a potential gaseous fuel from microwave-heated pyrolysis of waste automotive engine oil. Int. J. Hydrog. Energy 2012, 37, 5011-5021.

18. Lam, S.S.; Russell, A.D.; Chase, H.A. Microwave pyrolysis, a novel process for recycling waste automotive engine oil. Energy 2010, 35, 2985-2991.

19. Chen, K.S.; Yeh, R.Z.; Wu, C.H. Kinetics of thermal decomposition of epoxy resin in nitrogen-oxygen atmosphere. J. Environ. Eng. 1997, 123, 1041-1046.

20. Chen, K.S.; Chen, H.C.; Wu, C.H.; Chou. Y.M. Kinetics of thermal and oxidative decomposition of printed circuit boards. J. Environ. Eng. 1999, 125, 277-283.

21. Luda, M.P.; Balabanovich, A.I.; Zanetti, M.; Camino, G. Thermal decomposition of the retardant brominated epoxy resins. J. Anal. Appl. Pyrolysis 2002, 65, 25-40. 
22. Barontini, F.; Marsanich, K.; Petarca, L.; Cozzani, V. Thermal degradation and decomposition products of electronic boards containing BFRs. Ind. Eng. Chem. Res. 2005, 44, 4186-4199.

23. Chien, Y.C.; H.P.Wang; Lin, K.S.; Huang, Y.J.; Yang, Y.W. Fate of bromine in pyrolysis of printed circuit boardwastes. Chemosphere 2000, 40, 383-387.

24. Blazsó, M.; Czégény, Z.; Csoma, C. Pyrolysis and debromination of flame retarded polymers of electronic scrap studied by analytical pyrolysis. J. Anal. Appl. Pyrolysis 2002, 64, 249-261.

25. Menéndez, J.A.; Juárez-Pérez, E.J.; Ruisánchez, E.; Bermúdez, J.M.; Arenillas, A. Ball lightning plasma and plasma arc formation during the microwave heating of carbons. Carbon 2011, 49, 346-349.

26. Sun J.; Wang, W.L.; Ma, C.Y.; Dong, Y. An exploratory study of electronic waste treatment: microwave-induced pyrolysis. In Proceedings of 2010 Asia-Pacific Power and Energy Engineering Conference, Chengdu, China, 28-31 March 2010; pp. 1-4.

27. Sun J.; Wang, W.L.; Liu Z.; Ma, C.Y. Waste printed circuit boards reclamation by microwave-induced pyrolysis and featured mechanical processing. Ind. Eng. Chem. Res. 2011, 50, $11763-11769$.

28. Wang, W.L.; Liu, Z.; Sun, J.; Ma, Q.L.; Ma, C.Y.; Zhang, Y.L. Experimental study on the heating effects of microwave discharge caused by metals. AIChE J. 2012, doi: 10.1002/aic.13766.

29. Sun J.; Wang, W.L.; Liu, Z.; Ma, C.Y. Study of the transference rules for bromine in waste printed circuit boards during microwave-induced pyrolysis. J. Air Waste Manag. Assoc. 2011, 61, $535-542$.

30. Sun J.; Wang, W.L.; Ma, C.Y.; Dong, Y. Study on pyrolysis characteristics of electronic waste. In Proceedings of the International Conference on Chemical, Biological and Environmental Engineering (CBEE 2009), Singapore, 9-11 October 2009; Kai, L., Ed.; World Scientific Publishing: Singapore, 2009; pp. 13-16.

31. Chiang, H.L.; Lin, K.H.; Lai, M.-H.; Chen, T.C.; Ma, S.Y. Pyrolysis characteristics of integrated circuit boards at various particle sizes and temperatures. J. Hazard. Mater. 2007, 149, 151-159.

32. Narayan, R.; Antal, M.J., Jr. Thermal lag, fusion, and the compensation effect during biomass pyrolysis. Ind. Eng. Chem. Res. 1996, 35, 1711-1721.

33. Ceamanos, J.; Mastral, J.F.; Millera, A.; Aldea, M.E. Kinetics of pyrolysis of high density polyethylene: Comparison of isothermal and dynamic experiments. J. Anal. Appl. Pyrolysis 2002, 65, 93-110.

(C) 2012 by the authors; licensee MDPI, Basel, Switzerland. This article is an open access article distributed under the terms and conditions of the Creative Commons Attribution license (http://creativecommons.org/licenses/by/3.0/). 